\title{
55. Why are we so much more afraid of COVID-19 than of climate change? Early lessons from a health crisis for the communication of climate change François Gemenne and Anneliese Depoux
}

As most countries of the world were affected by the COVID-19 in the first months of 2020, many of them took radical measures to contain the spread of the pandemic. Thousands of flights were cancelled, schools and shops were closed, industrial production was slashed, people were confined at home. The whole economy came to a standstill.

Many of these measures resulted in very significant cuts in greenhouse gas emissions and atmospheric pollution. Estimates by Carbon Brief reckon that greenhouse gas emissions in China were down 25 percent in February 2020, while fine particle levels were down 20-30 percent across the country (Myllyvirta, 2020). Global air traffic was reduced by 4.3 percent that same month - and this was before the ban on flights from Europe to the US imposed by US president Donald Trump in early March.

Paradoxically perhaps, some of these measures had a positive impact for human health. Marshall Burke, from the Earth System Science Department at Stanford University, calculated that 'reductions in air pollution in China caused by this economic disruption likely saved twenty times more lives in China than have currently been lost due to infection with the virus in that country' (Burke, 2020).

Though the global impact of the pandemic on climate change will be difficult to assess, given the far-reaching economic, political and social implications of some of the containment measures, one thing is certain: it is possible for world leaders to take urgent and radical measures in the face of an imminent threat, and for the populations to accept them. Yet we haven't been able, so far, to take similar measures to confront climate change. Until the pandemic outbreak, and despite many calls from activists and scientists alike to declare a state of 'climate emergency', emissions were still rising at a yearly increase of 1 per cent. 
While we were ready to treat COVID-19 as a major emergency, obviously we were not ready, or not willing, to do the same for climate change. COVID-19 was - and rightly so - treated as a major emergency, with immediate application of radical measures, following scientific advice, to contain it. The threat of climate change has not induced such radical measures so far. To put it simply: we are much more afraid of the COVID-19 than we are of climate change. And this raises a series of questions regarding the way we communicate about climate change.

In no way are we saying here that we shouldn't be afraid of COVID-19, or that it is a minor threat. On the contrary, the radical responses implemented by many governments are impressive - albeit sometimes too tardy - and we believe this holds lessons for our communication on climate change. In the midst of the health crisis, many were prompt to point out the similarities between climate change and the pandemic. Both were global crises, requiring urgent responses on the basis of scientific advice. Therefore, many activists were quick to suggest that the measures implemented to fight against the spread of the pandemic had to be replicated to slow down climate change: 'we must respond to climate change like we're responding to coronavirus', argued Zero Hour founder Jamie Margolin in Teen Vogue magazine. ${ }^{1}$ Others went a step further and claimed the pandemic was an 'ultimatum of nature', a 'revenge of the Earth' or even 'good news for the environment'. \#WeAreTheProblem was a popular hashtag on social media as many countries were in lockdown, as if the pandemic was eventually a way for nature to reclaim its rights.

In this chapter, we argue that climate change and the COVID-19 pandemic are not similar crises, even though they present some striking similarities. This has important consequences for the response measures to be deployed, but also for the way we communicate about climate change. Here we try to outline some early lessons from the health crisis to improve our communication on climate change.

First, if we are we so much more afraid of COVID-19 than we are of climate change, this is probably because we're afraid of getting sick ourselves. A central element of the response lies in the proximity and immediateness of the threat. We are all afraid (or should be afraid) of contracting the virus personally, while climate change still seems perceived as a concern for others - for the next generation, or far-away countries. We are well aware that COVID-19 is a threat for ourselves, while climate change remains perceived as a threat that will mostly affect others. We are afraid of getting contaminated with the virus, while we don't see climate change as contagious. Psychological research has shown that contagion - or the threat of contagion - is a powerful driver of new social norms, which we adopt to protect ourselves (Sperber, 1996).

And perhaps we should acknowledge that we, researchers, bear some responsibility for this. Climate models are calibrated on the long run, and 
policy objectives target 2050 or 2100 . Rather than putting forward a short-term objective, the Paris Agreement insists on a long-term objective, a maximum temperature by 2100 , a date that far exceeds the lifetime of most of those who are reading the present chapter - and certainly of all those who signed the Paris Agreement itself. Similarly, while industrialized countries are badly hit by the pandemic, research has consistently stressed that countries most vulnerable to climate change impacts are developing countries, or that the poorest, most marginalized populations would be disproportionately affected by climate impacts. While these facts are indisputable, they also create a social distance between climate change and those who should act to contain it.

This suggests that we should insist more on the immediate consequences of climate change, and less on the long-term objectives. In an op-ed published in The Guardian in late January 2020, George Monbiot suggested dropping these long-term objectives - which he found to be counterproductive - to adopt instead a maximalist approach (Monbiot, 2020). This maximalist approach is the one adopted by most governments in the face of the COVID-19 crisis: they don't seek to reduce the infection rate by a certain percentage, but rather to 'flatten the curve' as much as possible. And this is how the radical measures of containment are justified - without these, there's a fear that the crisis would become unmanageable for hospitals and health services.

Second, the impacts of climate change on public health have not been sufficiently emphasized in public debates. Yet, there is ample scientific evidence that climate change bears some significant health impacts. Every year, the annual report of The Lancet Countdown initiative reviews these impacts, which range from cardiovascular troubles to allergies and infectious diseases such as dengue or malaria (Watts et al., 2019). The World Health Organization reckons that climate change could claim 250000 additional lives per year between 2030 and $2050 .{ }^{2}$ Research has consistently shown that the arguments about the public health impacts of climate change are amongst the most persuasive, and most likely to induce behavioural changes (Maibach et al., 2018). Yet, these arguments are not often put forward in public debates on climate change (Depoux et al., 2017), even though the COVID-19 crisis shows once again the persuasiveness of such points.

Third, it is important to acknowledge that the reason confinement measures are widely accepted - though not always perfectly applied - is also because they are temporary. If radical confinement measures, such as curfew or limitation of air travel, were permanent, then it is likely they would be less accepted by the population. In that sense, we should be very careful about treating climate change as a 'crisis': a crisis is temporary and suggests a return to normality at the end of the day. Global warming is an irreversible transformation of the Earth's climate. There will be no return to 'normal': temperature will not decrease, sea-level will not go down - at least not for a really long 
time - and there will be no vaccine against climate change. Thus, the measures that need to be taken to address climate change cannot be temporary: they need to become permanent features of our economy, politics and way of life. Therefore, one should not make the mistake of assuming that radical measures taken against COVID-19 could easily be replicated against climate change: the former are only accepted because they are of a temporary nature.

Furthermore, the idea that we should consider the pandemic as a 'general rehearsal' before climate change can be deeply counterproductive: if people are under the impression that the fight against climate change requires the economy to be on standstill, they are likely to reject any measure taken against climate change in the future. Surely one will not look back fondly on the confinement period as the golden age of the fight against climate change.

Finally, individual knowledge is often assumed to be a key factor in the mobilization against climate change - education, for example, is often presented as a crucial weapon in the fight (Anderson, 2012), as if action would only be taken once everyone were knowledgeable about climate change and its impacts. Yet, measures against the coronavirus pandemic have been imposed on a top-down basis, not on a bottom-up basis: people didn't decide to confine themselves spontaneously. People had little medical knowledge about the virus, and yet accepted the measures in the face of an imminent danger. This holds an important lesson for climate change: if we count on every individual to do one's part, then radical action might just never materialize. Top-down measures will be needed: despite the many actions and measures taken spontaneously by civil society, legal frameworks will need to be implemented by governments.

Climate change and the COVID-19 pandemic share many characteristics: both are of global nature, requiring radical responses on the basis of scientific assessments. In both cases, these responses are required first and foremost to protect the most vulnerable. In that regard, the confinement measures taken against COVID-19 represent a remarkable display of solidarity: whole countries were in complete lockdown to protect the elderly and those with fragile health. But this solidarity was often confined to national borders: there was no global response to the crisis, but rather a myriad of different national responses, sometimes very different from one another. Climate change will require solidarity beyond borders, not just within borders - whereas the effects of closing borders to slow down the spread of the virus can be disputed, there's no question that climate change can't be stopped at the border.

There are important lessons to take away from the COVID-19 crisis for the communication of climate change. Let's not assume, however, that the measures deployed against the pandemic can be replicated as such to fight climate change. Despite their similarities, climate change will require different solutions. But the coronavirus crisis tells us it is possible to take urgent, costly 
and radical measures, and gives some hints as to how these can be accepted by the population.

\section{NOTES}

1. Jamie Margolin, 'Coronavirus shows us rapid global response to climate change is possible', Teenvogue.com, 18 March 2020, accessed 3 September 2020 at https:// www.teenvogue.com/story/coronavirus-response-climate-crisis.

2. World Health Organization (2018), 'Climate change and health', accessed 3 September 2020 at https://www.who.int/news-room/fact-sheets/detail/climate -change-and-health.

\section{REFERENCES}

Anderson, A. (2012), 'Climate change education for mitigation and adaptation', Journal of Education for Sustainable Development, 6 (2), 191-206.

Burke, M. (2020), 'COVID-19 reduces economic activity, which reduces pollution, which saves lives', G-FEED.com, accessed 15 March 2020 at http://www.g-feed .com/2020/03/covid-19-reduces-economic-activity.html.

Depoux, A., Hémono, M. and Puig-Malet, S. et al. (2017), 'Communicating climate change and health in the media', Public Health Reviews, 38, article 7.

Maibach, E.W., Kreslake, J.M. and Roser-Renouf, C. et al. (2015), 'Do Americans understand that global warming is harmful to human health? Evidence from a national survey', Annals of Global Health, 81 (3), 396-409.

Monbiot, G. (2020), 'Let's abandon climate targets, and do something completely different', The Guardian, 29 January.

Myllyvirta, L. (2020), 'Analysis: coronavirus has temporarily reduced China's $\mathrm{CO}_{2}$ emissions by a quarter', CarbonBrief.org, 19 February, accessed 15 March 2020 at https://www.carbonbrief.org/analysis-coronavirus-has-temporarily-reduced-chinas -co2-emissions-by-a-quarter.

Sperber, D. (1996), La Contagion des Idées, Paris: Odile Jacob.

Watts, N., Amann, M. and Arnell, N. et al. (2019), 'The 2019 report of The Lancet Countdown on health and climate change: ensuring that the health of a child born today is not defined by a changing climate. The Lancet, 394 (10211), 1836-78. 